\title{
Study on Educational Potential of Art
}

\author{
Maria Tarasova \\ School for the Humanities \\ Siberian Federal University \\ Krasnoyarsk, Russia \\ E-mail: mariavtarasova007@gmail.com
}

\begin{abstract}
Since the contingency factor in education forces the researchers and practitioners from around the world to unite their efforts in scheming as many educational strategies as possible, it is important to outline the project of building the higher education program on art culture ideals. Art can be an insatiable resource for educational techniques on all stages of education, but in the higher education system it may be especially important in shaping the students personal and professional worldview. The investigation of possibilities to model students' world outlook in educational situations of higher school by means of realization ideal-creating mechanisms of art culture is undertaken in the research. The author of the article explores the possibilities to extrapolate art culture mechanisms on the educational field of universities. The role of visual thinking in higher education is examined. The art image is determined as an educational space and as an educational instrument. The rules of constructing an educational model are revealed based of the same principles as those that bring the art image to existence. One of main hypotheses introduced in the text is that the rules of art communication should be understood as a method to model students' world outlook.
\end{abstract}

Keywords—art; higher education; university; ideal; culture; visual thinking

\section{INTRODUCTION}

The idea of necessity to reform higher education in modern Russia and to introduce innovational educational technologies needs a more profound and fundamental basis. Accurate and, if possible, full description of higher education goals may become the starting point for strategic and tactic planning of essential changes in educational system organization [1]. Once the federal law of two-level bachelor/master system had been carried out it automatically took the goal of producing graduates as "specialists" away of educational priorities. Educating bachelors and masters means producing an educated person, him (or her) being non-specialized in any particular sphere. In such educational approach the major value is to obtain general acting schemes of self-creation, self-modeling. These schemes will help an individual to find freely his own position in the space of multiple capacities for professional realization.

In order to make the model of a man who is free in his educational orientation working and effective it is necessary to determine basic values that construct the ground of the educational system. The gap between theory and practice makes us distinguish the idea of education and it practical realization in the institutes of education. Answering the question about the true essence of the educational action and correcting the definition of the education pattern may become ways to make the educational practice closer to fulfillment of education paradigm.

Traditionally education is determined as "a process and a result of acquiring abilities, skills and theoretical knowledge" [2, p. 578]. In English one may find such definitions as "the process of training" while the verb "to educate" means "to train the mind, character, and abilities", according to Oxford Dictionary and Thesaurus of Current English. Definitions do not differ much. This kind of definitions has not only been fixed in theory but it is also applied to pedagogical practice. Actually this definition clearly demonstrates immobility of existing educational models in which a student is considered to be a passive object of "streams" of abilities, skills and knowledge directed towards him. The major shortage of modern educational practical situations is the fact that the student is devoid of active subject position.

On finding the solution of this problem it may be effective to understand the essence of an education phenomenon and to answer the question what culture mechanism may be applied to the educational practice in higher education institutes to let a student get a subject position both in education and in life.

\section{The Creative MeAning OF the Process of EDUCATION}

Education is a creative process. In all etymological explanatory constructions there is a conception of some ideal measure, of the pattern that regulates the creating process. In Russian language the word "education" may be literally translated as "image-making". This proves the word "image" to be a root and an origin of the concept "education". An image serves as an instrument of education. The education is correctly to be understood as a process of creating an ideal image of a person.

A paradigm of understanding an image as an ideal pattern was first suggested by Plato's philosophy and later developed in Plotinus' theory. After that it was accepted as a basic concept of the Christian educational system. The analysis of the human educational experience shows that education means ideal-creating. Does the ideal ever appear in our modern educational practice? Answering this question 
one may presume that the place of an ideal model in education is taken by a professional, a specialist in a sphere that a student had chosen and was trained to get involved. It may be an ideal "mathematician", "art-critic", "PR-manager", etc. But this figure cannot be called the perfect ideal because it is not present in them but is vaguely visible in some more or less far future. As the higher education gets gradually free of connection with the "profession" of its students, the ideal may be understood as one of the educated person.

But it is important to remember that the ideal model in education is never a certain person, it is never "a figure" no matter real or abstract. An ideal that regulates the whole educational process is always wider that the human embodiment. Above all, the ideal is a scheme of action. Ideal schemes of action form a person's attitude to life. The main objects of any educational situation are the operations of a man's ideal correlation of his own individual substance to the subject substance of the world.

An age of a person who finds oneself in a situation of getting higher education is on the border between teens and youth. The peculiar transitional feature of this age when a person enters higher education system must become a base for organization of all training programs. It is the time of the first and mostly intensely felt encounter of one's own subject self and an object world. For an individual both subject and object structures are still developing; so any kind of interaction greatly influences the formation of a new quality, i.e. an image of a relationship between a man and a world an image of a world outlook.

According to the Russian psychologist Daniil B. Elkonin [3], a certain "leading type of activity" is specific for any age. Then it is possible to presume that the leading type of activity in a student time is a dialectic correlation of a "project" of future activity to a certain program of activity that is offered to a student in reality. The "project" stands here for a mental image of one's own future. It is created in a student's mind in relation to his professional activity.

It is important to remember the ideal status of the named leading activity of a student. It is happening in the subject's mind. That differs from the situation in an adult life. During the student time there are possibilities to correlate the projective planning of the future position to the offered schemes of action and to grade these schemes as relevant or irrelevant to the "project".

The age situation provides all the ground and educational conditions only help to organize a student's higher education time as time for ideal modeling a student's self, as well as his ways of relationship with the world. And also it is time to model a student's active future. For a person a student age is time for reflection on oneself and one's abilities yet without bringing them into action for real. Studying time is a unique period in the development of an individual worldview. It is the time fully open for ideal activity, reflective projecting when the subject of a project is individual's own life.

On the one hand, the higher education goal is to create a student's individual self-educating and personal selfdevelopment model $[4,5]$, to teach a student methods to build an individual "world picture" and to know how to make this picture an operative one. On the other hand, this goal may be achieved only by modeling the conflict encounter of two sides of the relationship with the world. Only this intended conflict leads to development of a student's personal "world picture". In order to realize modeling needs of this age it is necessary to activate thinking mechanisms, which are adequate to the creative characteristics of the student age.

Theoreticians and practitioners of education must always bear in mind that education is a culture mechanism. Culture is an ideal-creating part of a human activity [6]. The culture is dedicated to creation and reproduction of ideals. The basic component of culture is art culture [7]. The ideal in culture may have different power of representation. Works of art may be able to represent only a finite world, serve to communication between a person and other people, etc. But some artworks are capable to organize relationship of a man with the absolute essence, and they are perfect ideal patterns. The value of a masterpiece is determined by its communicative potential: the dialogue-relationship of a viewer with such an artwork makes one start a fuller dialogue with the universe. The main function of culture is the creation, i.e. education of a human being.

The conceptual and functional relationship between education and culture serves as a ground for applying the culture working mechanism to the system of educational institutes. The education may be called a medium sphere of culture that involves more and more new participants and cocreators to the ideal-creating practice.

Involving ideal-creating schemes of action that comprise culture into the basics of the educational practice may become the solution of problems in the work of educational institutes. The educational potential of art culture ideal models - masterpieces of art - should be used on all levels of educating. Psychological features of a student age make the higher education the most attractive stage of intended and fully comprehended usage of the dialogue with works of art as a means to model life-determining positions and programming of a human worldview [8].

\section{THE DEVELOPMENT OF VISUAL THINKING BY MEANS OF COMMUNICATION WITH WORKS OF ART}

The application of the art culture principles to the theory and practice of education calls for development of the adequate thinking skills. The ideal-creating process, realized in an intermediate contact with a work of art, calls for the development of the thinking operations produced by visual thinking [8].

The visual thinking is characterized by mental operation of iconic images and symbols [9]. The visual thinking is not only actively studied by psychology and art-criticism but it is occasionally used in education. But today there is still no system use of visual thinking opportunities for discovering the whole educational potential of art works.

The visual thinking is defined as "mind activity based on operation of perceptual ... spacious structured schemes" [2, 
p. 138]. Operating by perceptual images the visual thinking makes it possible to see its results, to lead them out of abstract state of existence into a perceptive area. Structural appearance is mainly characteristic for the visual constructions born by the visual thinking. One of the key functions of the visual thinking is to foresee new methods of acting with the given perceptive material [9]. The function of foresight proves that the visual thinking enables to see a future of an object.

The psychological appeal of a person in his student age to reflection over one's own capacities and ways to relate with the world may be realized in the desire to model and to try the whole specter of worldview points. The appeal is satisfied in the methodological functioning of the visual thinking. The fact that the student age is congenial to mostly ideal relationship with the world should be fully appreciated if knowing that it is combined with a student's essential need to try himself and also to try the world, and then to program one's own future. Only visual thinking may satisfy this need.

The visual thinking may be correctly understood as modeling, projecting, constructing and foresight. Foresight is an essential competence for students of higher education [10]. When encountering the constructive schemes of the visual thinking the creative demands of the intentional student age transform perceptual images into adequate educational mechanisms [11]. Constructive schemes of the visual thinking make the visible world structured and help to orient oneself in this world. The age when the person is mostly ready for reflective modeling of an individual worldview is in great necessity for the creative thinking. That important role that perceptual images play in human relationship with the world requires for involving visual thinking practice into the higher education sphere [12].

The proof of importance of the visual thinking for a man leads to the necessity to define certain methods and technologies of developing visual thinking. An art image is a new emergent born out of the dialogue-relationship process between a viewer and a work of art [13]. A work of art exists only as an art image. An art image is operational. The basic principle of a coming-to-be process of art image is an intersection of operations produces by both a viewer and a work of art. An art image representing the whole of interaction between a man and the world is an image born as a result of ideal operations of a masterpiece and ideal operations of a viewer [14]. This kind of an art image is a perfect product of the visual thinking. It shows all cognitive, communicative and ontological capacities of art.

To set an example of how the work of art educates a person we can look at the painting "Where do we come from? What are we? Where are we going" by Paul Gauguin.The work of art sends its primary educating message via the language of composition.Here the composition is formed be means of waving lines. The lines come together in a compositional formula that is called a lemniscate.Geometrically a lemniscate reproduces a mathematical sign of eternity. Two round forms tend to turn into each other on a non-stop basis.Compositional formula shows an eternal circulation that is going on in the depicted
world.The art makes viewers think and then visual concepts "rotation"and "recurring" appear. Another type of compositional lines is presented in sine curves. Ascending and descending rhythms form visual notions "flow" and "waving". The viewers' visual thinking starts working again and creates the visual concept "the river of life". And every character appears to be a part of a wave in a stream of life.

In the left upper part of the picture on the golden background we can read questions in French "D’ouvenonsnous? Quesommesnous? Ouallonsnous?". They mean "Where do we come from? What are we? Where are we going?" The work of art starts its dialogue with the viewer by setting up an educational problem and then it stimulates its solving. In other words, these questions mean, "What is a human being, his life and his death"? At first the process of visual reading of answers of these questions begins from right to left. It provokes the feeling of intellectual discomfort in the viewer who tends to read the picture in the opposite way. The baby, the mature fruit gatherer and the old woman personify three phases of a human life.According to this scheme the answers may be transcribed in the following way. "Where do we come from?" - from the non-existence before our birth; "What are we?" - reaching towards the fruit of life; "Where are we going?" - to the non-existence after death.Therefore, the movement of the viewer's eye from right to left presents the stereotype of the life development from birth to death. As a result, the viewer faces the general formula of life - people get born, tear off the fruit of life, get old and end their life journey. But the picture proposes another way to answer the questions of a lifetime. In the left part of the picture besides the representation of the fear and the despair of the human mortality there is also a statue of goddess depicted on top the hill. The statue is a representative of the higher world that knows no fear and no death. The goddess is the character that gives another lesson on life and death, as she speaks of the final in a life journey as of the beginning of another one along the river of eternity. As a result, this border of the human life is simultaneously formed by two opposite notions — "the end" and "the beginning" as a transition to the other.

As the viewer starts using her intellectual vision to move backwards, she returns to the figure of the sleeping baby. Infancy is represented as a point from where all comes and where all eventually returns. The viewer rediscovers the meaning of the compositional scheme of rotation which is a visual presentation of infinity. Paul Gauguin said: "Life is so short - you have no time to prepare for eternity". The work of art is a tuning fork that attunes for the preparation to eternity.And this is a general meaning of art. The work of art shows how vanity, fear and doubts step aside and a different understanding of life comes to the foreground. It shows that a moment and eternity are the one. The viewer discovers new meanings of answers to the questions of the title. There is no development from the beginning to the end but only eternity the man belongs to before, during and after his life.

The educational potential of this work of art may be understood in many aspects. First of all the work of art develops the capacities of the viewer in a human being. The viewer does not merely look but is the one who actually sees 
the signs and their meanings. As a result the viewer may be defined as the thinker, who is asking questions and following the messages, who is never satisfied by the found answers and is ready for new steps of exploring.

The work of art also teaches comprehending the real meanings of such life stages as childhood, maturity and old age. Thedepicted story is not about some distant and unknown Tahitians. The viewer finds out that it is rather a visual story about all the people who share their destiny of walking along their own way of life. This work of art demonstrates the ideal human being and its ideal relationship with the divine Universe. Simultaneously the work of art allows every viewer to try this ideal role on.

Art is one of the bestresources for a person to get to know oneself.Different works of art can give us different life lessons. For instance, the "Noblewoman Morozova" by Vasiliy Sourikov can show how a human can challenge the official rules and get entangled in the network barriers. The painting "Liberty" by Eugene Delacroix can make the viewer understand how easily the mankind can get to hating and slaughtering itself. The masterpiece "Giaconda" by Leonardo da Vinci is the work of art that may demonstrate how the fragile human soul receives and transmits the energy of the spirit to the world. "The ball at Moulin de la Galette" by Pierre August Renoir teaches its viewer on how marvelous the holiday of the life dance enveloped by golden divine lightcanbe.

Exploring the educational potential of art gives an opportunity of getting insight into the most effective strategies that the mankind has produced for understanding itself and the ways of communicating with the world.

There are different modes of realizing the educational potential of art in the institutions of higher education. One of the most effective modes is introduction of the course "Visual Thinking" that allows the student to develop their visual thinking and to outline better strategies to shaping their worldview. For instance, in Siberian Federal University the course "Visual thinking: theory and practice" is introduced to students of various engineering specializations, as well as to the students of SibFU Honors College where the best students of all academic schools of the university study. The course introduces the students to the strategies and tactics of the development of their visual thinking. By studying works of visual art and other products of visual thinking the students learn to enhance their own visual thinking abilities. The course aims at the improvement of students' creativity, projecting skills, spatial intelligence, modeling and operating visual images. The objectives of the course include the intentions to master the technologies of improvement individual's visual thinking skills; to obtain the skills of idea-expression and idea-implementation; to gain insight into the works of visual art as gnoseological and onthological acting models; to learn the theory and practice of creating products of visual thinking — models of scientific, professional and philosophic concepts.

\section{CONCLUSION}

The construction of the world outlook via participating in the development of an art image lets a man model an individual picture of the world [15]. An education by means of introducing into an art image development turns out to be a multilayered process in which a viewer inconspicuously comprehends the depths of his own soul while understanding the meanings of the artwork signs. The creation of an art image means self-creation for the viewer as a person. While acting as an addressee, as a speaking partner and as a coauthor of the artwork in his operations of conceiving an art image the viewer gets involved into a dialogue relationship with himself and with the world. That is the way a viewer becomes his own creator and a creator of the world in an ideal modeling of an individual relationship with the world. Dialogue skills are vital for educational activities $[16,17]$ and can be established by communicating with works of art.

The world outlook conceived in the space and by means of art communication serves as a model of the relationship between a human being and the world constantly reflected in each other. The model of the world needs a viewer for its full actualization [18].

The works of art as ideals produced in the sphere of art culture may be effective educational tools when applied tothe higher education technologies. The fundamental program of involving students into a space of art communication via acquiring practical skills of visual thinking may become a basis of the whole educational process in universities. Notwithstanding the profile chosen by a student (humanities, or natural science, or techniques) the educational system that is aimed to achieve the goal of creating an educated man [19, 20] who is aware of multiple strategies of self-modeling in the world should actualize the educational potential of the visual art.

\section{REFERENCES}

[1] S.A.Prokopenko, T.S. Selevich."Research and development of the understanding of the essence of university", Philosophy of Education, 16,2015 .

[2] Modern Dictionary of Philosophy, edited by V.E. Kemerov. LondonFrankfurt-upon-Mein-Paris-Luxemburg-Moscow-Minsk. Panprint, 1998.

[3] D.B. Elkonin. "Selected psychological works", Moscow. Pedagogics Press, 1989.

[4] G.P. Schedrovitskiy. "Lectures on pedagogics",Moscow, NasledieMMK Press, 2007.

[5] V.V. Davydov."The theory of developing education", Moscow, Pedagogics Press, 1996.

[6] D.V.Pivovarov, A.V. Medvedev. "History and philosophy of religion", Yekaterinburg-Nizhnevartovsk, Ural University Press and Nizhnevartovsk pedagogical institute Press, 2000.

[7] M.V. Tarasova."Culture and education: principles of correlation", Krasnoyarsk, Siberian Federal University Press,2012.

[8] R.Arnheim. "Visual thinking", University of California Press, Berkley and Los Angeles, California, University of California Press, Ltd., London, England, 1997.

[9] V.I.Zhukovsky, D.V. Pivovarov. "Visible essence (visual thinking in fine arts)". Sverdlovsk, Ural University Press, 1991. 
[10] D.V. Evzrezov. "About the foresight of Russian education",Philosophy of Education, 4, 2015.

[11] S.P.Lomov, L.G. Medvedev. "Fine arts as a factor of formation of the scientific worldview of schoolchildren", Philosophy of Education, 6, 2015.

[12] S.A.An, E.V.Ushakova, N.V. Nalivayko. "Formation of philosophical outlook of the students in modern education", Philosophy of education, 5, 2015.

[13] V.I. Zhukovsky. "The theory of visual art", Saint Petersburg, Alethea Press, 2011

[14] M.V. Tarasova."Educational potential of art culture ideals", Herald of Moscow State University of Culture and Fine Arts, 6, 2010, pp. 144149 .

[15] T.S.Kosenko, V.I. Panarin. "World outlook basis of modern Russian education", Philosophy of Education, 4, 2010,pp.207-212.

[16] V.I. Kudashov. "The dialogueness phenomenon and modern education”, Irkutsk,IrkutskStateUniversityPress, 1998.

[17] T.S.Kosenko, N.V. Nalivayko. "The concept of dialogue in the modern educational system, Philosophy of Education, 3, 2010,pp. 246-253.

[18] V.I.Panarin, V.I.Parshikov, S.I. Chernykh. "Humanitarian culture as a condition of educational transformation", Philosophy of Education, 1, 2016

[19] N.V.Nalivayko, P.V.Ushakov, E.V. Ushakova. "The global anthropic crisis and the key role of education in the fate of the world", Philosophy of Education, 1, 2016.

[20] N.V. Nalivayko. "Philosophy of education: formation of the concept", Novosibirsk: Siberian Department of Russian Academy of Science Press, 2008 